\title{
Unsuccessful cardiopulmonary resuscitation in a 46-year old woman with malignant disease and severe refractory hypoglycaemia
}

\author{
Jerica Zaloznik ${ }^{1, \star}$, Gregor Prosen ${ }^{1}$
}

${ }^{1}$ University Medical Center Maribor, Department of Emergency Medicine, Ljubljanska ulica 5, 2000 Maribor, Slovenia

\section{*Correspondence}

jerica.zalo@gmail.com

(Jerica Zaloznik)

\begin{abstract}
Introduction: Severe hypoglycaemia carries high short-term mortality. When associated with malignancy, it is interestingly highly dependent on increased glucose consumption due to glycolytic metabolism preference. There is no general consensus on the therapy in end-stage malignant disease.

Case report: A 46-year old female with a recently diagnosed Hodgkin lymphoma presented in September 2019 to the emergency department with weakness, chills and fever. Apart from the diffuse lung interstitial syndrome, sinus tachycardia and respiratory collapsing inferior vena cava, her vital signs and physical examination revealed no significant abnormalities. Hypoglycaemia was determined/detected in the laboratory findings. During the secondary assessment, she arrested and cardiopulmonary resuscitation was initiated. Peripheral glucose measurements showed that refractory hypoglycaemia was unresponsive to any glucose infusions. After the return of spontaneous circulation, laboratory findings revealed severe hyperglycaemia. Soon after, the patient arrested again and a decision was made to apply Intralipid emulsion. CPR ended unsuccessfully.

Conclusion: Septic shock with clinical markers of peripheral malperfusion can cause falsely low or immeasurable glucose levels in peripheral capillary blood.
\end{abstract}

\section{Keywords}

Hypoglycaemia; Malignancy-associated hypoglycaemia; Peripheral vasoconstriction; Cardiopulmonary resuscitation; Shock

\section{Introduction}

Hypoglycaemia is defined by the Whipple's triad: symptoms suggestive of hypoglycaemia, low plasma glucose concentration, and resolution of symptoms after glucose administration [1]. Severe hypoglycaemia $(<2.2 \mathrm{mmol} / \mathrm{L}(39.6 \mathrm{mg} / \mathrm{dL}))$ carries a high short-term mortality of about $20 \%$ [2]. Causes that are more common are medications used to treat diabetes mellitus, alcohol abuse as well as kidney or liver disease. Rare causes are starvation, tumours or sepsis. Definitions for refractory hypoglycaemia are unclear. Most reported cases describe "refractory" either as prolonged duration of hypoglycaemia (hours to days), high dose of dextrose (> $30 \mathrm{~g}$ glucose) to normalize sugar levels or prolonged infusion of glucose to maintain euglycaemia [3]. Unfortunately, no data are available on the mortality of patients with refractory hypoglycaemia. Malignancy-associated hypoglycaemia is the result of a combination of various factors, including insulinlike substance production by the malignant cells, impaired liver function with hepatic tumours, increased glucose consumption and autoantibodies to the insulin receptor [4]. Treatment is difficult; there is no general consent on the therapy in end-stage malignant diseases. Most authors describe $25 \mathrm{~g}$ of dextrose in $50 \mathrm{~mL}$ of fluid application, some add occasional glucagon shots, and corticosteroids are suggested as the last supportive measure [5]. As an alternative fuel source, even lipids were tested and encouraging but not definitive answers were given [6]. Here, we present a case of a 46-year old patient with a history of Hodgkin lymphoma who presented in septic shock that led to refractory hypoglycaemia and cardiac arrest, thus illustrating the difficulties faced in resuscitating malignancy patients with refractory hypoglycaemia.

\section{Case presentation}

A 46-year old female presented in September 2019 to the emergency department with weakness, chills and fever up to $38.8^{\circ} \mathrm{C}$ lasting for two days. Her medical history was remarkable for newly diagnosed classic Hodgkin lymphoma. Her vital signs on arrival were: blood pressure (BP) $101 / 61 \mathrm{mmHg}$, heart rate 117 beats/min, oxygen saturation $100 \%$, body temperature $35.3{ }^{\circ} \mathrm{C}$. On physical examination she looked distressed, but oriented, her skin was pale and subicteric. Heart auscultation revealed no additional sounds or murmurs, lungs were clear 


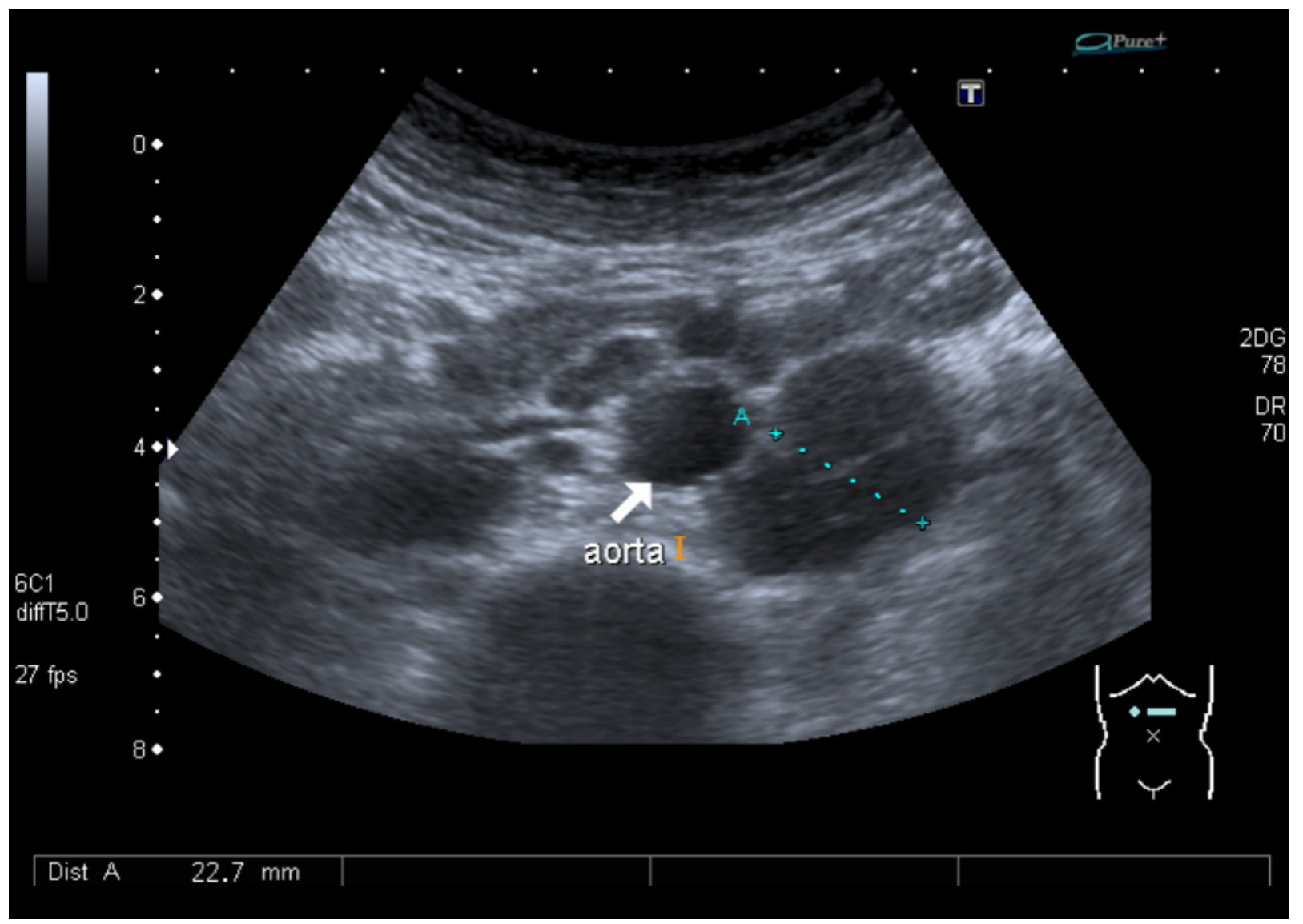

F I G U R E 1. Sonography Image of enlarged Paraaortic Lymph Nodes.

and her abdominal exam was without obvious gross abnormalities. Her first electrocardiogram (ECG) showed sinus tachycardia without pathologic markers. We performed bedside ultrasound (point-of-care ultrasound, PoCUS) revealing no free fluid in the abdominal cavity, enlarged paraaortic lymph nodes (Fig. 1), left ventricular function seemed normal, the right ventricle was smaller than the left and the inferior vena cava (IVC) was collapsing with respirations. On lung PoCUS she had diffuse lung interstitial syndrome, but no focal consolidations. Despite the initial $1500 \mathrm{~mL}$ of intravenous crystalloids, IVC remained collapsed, and her vitals deteriorated with systolic BP falling beneath $90 \mathrm{mmHg}$. The first bedside glucose measurement was $4.4 \mathrm{mmol} / \mathrm{L}(79.2$ $\mathrm{mg} / \mathrm{dL}$ ). She received $10 \mathrm{~mL}$ of $40 \%$ glucose and the control measurement of glucose level in her blood was $2.2 \mathrm{mmol} / \mathrm{L}$ $(39.6 \mathrm{mg} / \mathrm{dL})$. The first laboratory measurements were: serum lactate $16.4 \mathrm{mmol} / \mathrm{L}$ with elevated anion gap, C-reactive protein (CRP) $448 \mathrm{mg} / \mathrm{L}$, procalcitonin (PCT) $84 \mu \mathrm{g} / \mathrm{L}$ and signs of acute kidney and liver failure. While additional diagnostic procedures were attempted, she suddenly became haemodynamically unstable, lost consciousness and began breathing agonally. We commenced assisted ventilation and two minutes later she lost central pulses. Cardiopulmonary resuscitation (CPR) was initiated and we performed endotracheal intubation. The initial rhythm was pulseless electrical activity (PEA) with narrow QRS complexes and frequency of 60 per minute. She received $3 \mathrm{mg}$ of epinephrine during subsequent CPR. Glucose level during CPR was continually measured with two separate bedside devices and it was constantly and consistently "low" or unmeasurable. Glucose measurements are shown in Fig. 2. Three values were immeasurable, two were too low (marked as too low in the graph) and one (bedside measurement) at 19:12 was too high (marked as too high in the graph). The measurement on the other bedside device at the same time was $0.7 \mathrm{mmol} / \mathrm{L}(12.6 \mathrm{mg} / \mathrm{dL})$. Due to constantly low bedside glucose measurements, additional $120 \mathrm{~mL}$ of $40 \%$ glucose was infused during CPR and subsequent post-resuscitation period. After 10 minutes of initial CPR, the return of spontaneous circulation (ROSC) was achieved. However, after ROSC she required norepinephrine and vasopressin to keep her blood pressure within a normal range. After obtaining invasive arterial pressure measurements, her blood pressure was 130/100 $\mathrm{mmHg}$ and pulse 140 beats $/ \mathrm{min}$. In addition, laboratory analysis revealed severe metabolic acidemia $(\mathrm{pH} 6.7$, base excess $-25 \mathrm{mmol} / \mathrm{L}$, bicarbonate $3.8 \mathrm{mmol} / \mathrm{L}, \mathrm{pCO} 21.86 \mathrm{kPa}, \mathrm{pO} 2$ $13.8 \mathrm{kPa}$, lactate $22 \mathrm{mmol} / \mathrm{L}$ and blood glucose $65 \mathrm{mmol} / \mathrm{L}$ $(1170 \mathrm{mg} / \mathrm{dL}))$. A nasogastric tube was inserted, returning 450 $\mathrm{mL}$ of light green fluid. She received $30 \mathrm{~mL}$ of calcium gluconate and $50 \mathrm{~mL}$ of bicarbonate (the indications being hypocalcaemia and metabolic acidosis). After the initial elevation in blood pressure, a decrease in norepinephrine infusion was commenced with subsequent pressure drop and despite the correction of the norepinephrine dose, she arrested again. During the second CPR, she received $100 \mathrm{~mL}$ of Intralipid emulsion, was resuscitated for 35 minutes and received $7 \mathrm{mg}$ of epinephrine in total. Rhythm check revealed progressive widening of QRS complexes, resulting in electro-mechanical dissociation. After two hours of resuscitation, the patient 


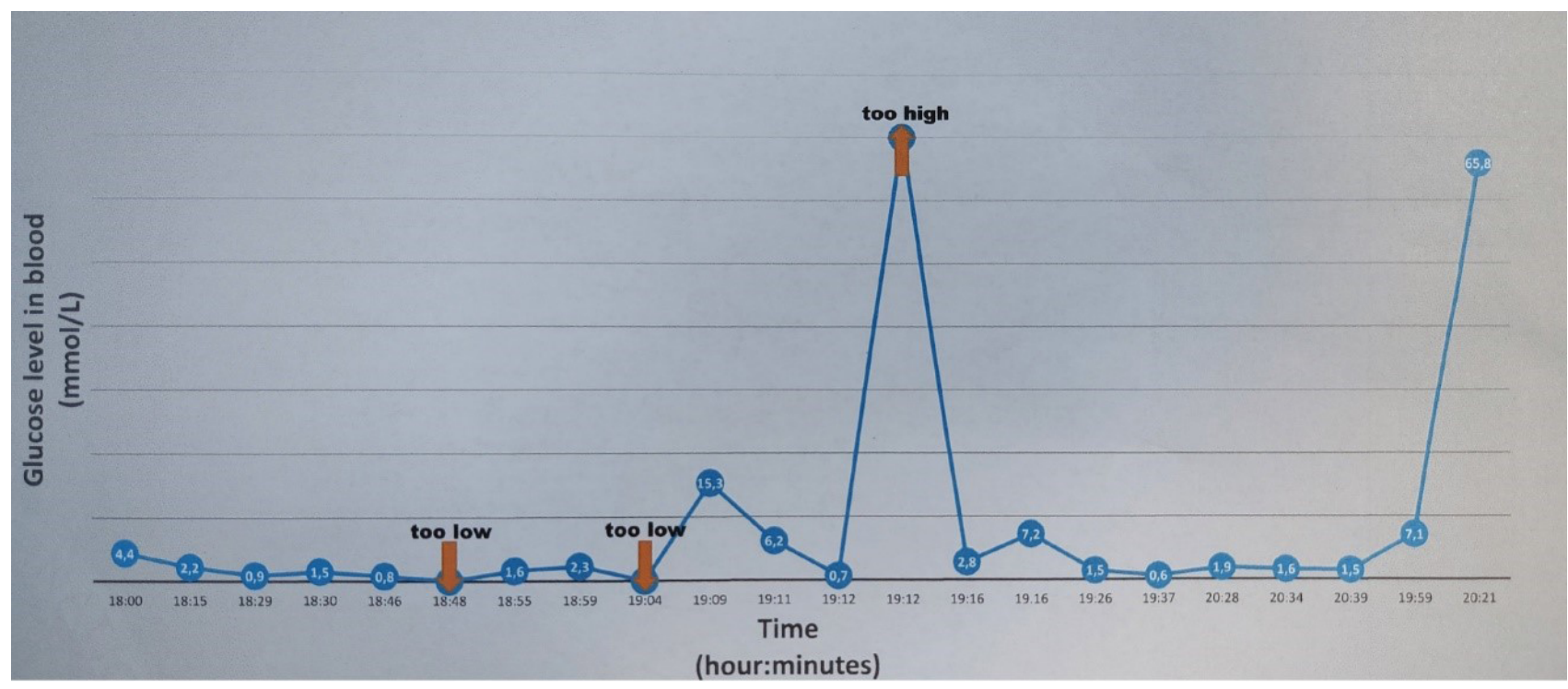

F I G U R E 2. Blood Glucose Measurements during Cardiopulmonary Resuscitation.

was declared dead. She received $2500 \mathrm{~mL}$ of crystalloids in total. The autopsy revealed acute respiratory distress syndrome (ARDS). Informed consent for publication was obtained from the patient's relatives.

\section{Discussion}

We present a case report of a young female, who was admitted to the emergency department in respiratory distress and septic shock. After primary survey, she decompensated and suffered cardiac arrest. Control samples of capillary blood were taken and consistently, with two separate bedside devices, have shown very low or immeasurable levels of capillary blood glucose that did not improve even after $120 \mathrm{~mL}$ of $40 \%$ glucose solution (48 grams of glucose). In addition, cyanosis and mottled skin were observed during CPR. Intralipid emulsion was used as the last resort due to its characteristic effectiveness as an antidote for lipophilic drugs [7, 8]. However, its failure proved that other already discussed causes of cardiovascular collapse were present. After reviewing the case, we hypothesized that such severe hypoglycaemia in capillary blood was due to severe peripheral clamp-down of circulation. The pathophysiology behind our statement is that in distributive shocks, first a vasodilated state occurs followed by a severe peripheral vasoconstrictive phase [9]. The association between hypoglycaemia and deaths from distributive shock was found to be particularly strong in the NICE-SUGAR study [10].

To our best knowledge, only a handful of similar cases have been reported in the medical literature. A case series by Shimizu et al. [3] presented three cases of hypoglycaemia with cardiac complications (Takotsubo cardiomyopathy, cardiac arrest and congestive heart failure) in starvation. The predisposing factor was starvation, whereas in our case it was a malignant disease. Malignancy-induced hypoglycaemia is the result of a combination of various factors, including insulin-like substance production by the malignant cells, impaired liver function with hepatic tumours, increased glucose consumption and autoantibodies to the insulin receptor [4].
The increased glucose consumption is especially interesting due to the fact that malignant cells tend to favour glycolytic metabolism rather than the much more effective oxidative phosphorylation (known as the Warburg effect) [11]. An important difference is that Shimizu et al. used thiamine analogues. It remains an intriguing question whether our patient would benefit from the same therapy.

This peripheral malperfusion is all the more severe, taking into account that with constant infusions of glucose we would expect a gradual increase in measurements, but consistently observed low level results. We have never before encountered a case with such severe interference of perfusion on capillary blood glucose measurements.

\section{Conclusions}

To conclude, septic shock with clinical markers of peripheral malperfusion can cause falsely low or immeasurable glucose levels in peripheral capillary blood.

\section{AUTHOR CONTRIBUTIONS}

Jerica Zaloznik: Data curation, Investigation, Visualization, Writing - original draft. Gregor Prosen: Conceptualization, Funding acquisition, Supervision, Writing - review and editing. Jerica Zaloznik and Gregor Prosen: Formal Analysis, Methodology, Project administration, Resources, Software, Validation.

\section{ETHICS APPROVAL AND CONSENT TO PARTICIPATE}

Our institution does not require ethical approval for reporting individual cases or case series. 


\section{ACKNOWLEDGMENT}

Thanks to all the peer reviewers for their opinions and suggestions.

\section{FUNDING}

None declared.

\section{CONFLICT OF INTEREST}

The authors declared no potential conflicts of interest with respect to the research, authorship and/or publication of this article.

\section{REFERENCES}

[1] Cryer PE, Axelrod L, Grossman AB, Heller SR, Montori VM, Seaquist ER, et al. Evaluation and management of adult hypoglycemic disorders: an endocrine society clinical practice guideline. Journal of Clinical Endocrinology \& Metabolism. 2009; 94: 709-728.

[2] Tsujimoto T, Yamamoto-Honda R, Kajio H, Kishimoto M, Noto H, Hachiya R, et al. Prediction of 90-day mortality in patients without diabetes by severe hypoglycemia: blood glucose level as a novel marker of severity of underlying disease. Acta Diabetologica. 2015; 52: 307-314.

[3] Shimizu K, Ogura H, Wasa M, Hirose T, Shimazu T, Nagasaka H, et al. Refractory hypoglycemia and subsequent cardiogenic shock in starvation and refeeding: report of three cases. Nutrition. 2014; 30: 1090-1092.

[4] Talwalkar PG. Severe and persistent hypoglycemia with lactic acidosis in an elderly lady with type 2 diabetes mellitus and lymphoma/leukemia: a rare case report. Diabetes \& Metabolic Syndrome: Clinical Research \& Reviews. 2019; 13: 648-650.

[5] Gonzalez F, Roshan R, Levene RS. Hypoglycemia management in nondiabetic adults at the end of life \#291. Journal of Palliative Medicine. 2015; 18: 552-553.

[6] Haywood SC, Bree AJ, Puente EC, Daphna-Iken D, Fisher SJ. Central but not systemic lipid infusion augments the counterregulatory response to hypoglycemia. American Journal of Physiology-Endocrinology and Metabolism. 2009; 297: E50-E56.

[7] Rothschild L, Bern S, Oswald S, Weinberg G. Intravenous lipid emulsion in clinical toxicology. Scandinavian Journal of Trauma, Resuscitation and Emergency Medicine. 2010; 18: 51.

[8] Weinberg GL. Lipid Emulsion Infusion: Resuscitation for Local Anesthetic and other Drug Overdose. Anesthesiology. 2012; 33: 76-77.

[9] Greer J. Pathophysiology of cardiovascular dysfunction in sepsis. BJA Education. 2015; 15: 316-321.

[10] Finfer S, Liu B, Chittock DR, Norton R, Myburgh JA, McArthur C, et al. Hypoglycemia and risk of death in critically ill patients. New England Journal of Medicine. 2012; 367: 1108-1118.

[11] Elhomsy GC, Eranki V, Albert SG, Fesler MJ, Parker SM, Michael AG, et al. "Hyper-Warburgism," a cause of asymptomatic hypoglycemia with lactic acidosis in a patient with non-Hodgkin's lymphoma. Journal of Clinical Endocrinology \& Metabolism. 2012; 97: 4311-4316.

How to cite this article: Jerica Zaloznik, Gregor Prosen. Unsuccessful cardiopulmonary resuscitation in a 46-year old woman with malignant disease and severe refractory hypoglycaemia. Signa Vitae. 2021;17(3):246-249. doi:10.22514/sv.2021.025. 